\title{
Un modelo estructuralista- keynesiano de determinación del tipo cambio real "óptimo" para el desarrollo económico brasileño: 1999-2015
}

André Nassif, Carmen Feijó y Eliane Araújo

\section{Resumen}

\begin{abstract}
El tipo de cambio real "óptimo" a largo plazo es aquel que, al redirigir eficientemente los recursos productivos hacia los sectores generadores y difusores de incrementos de productividad para la economía en general, tiende a acelerar y sostener el desarrollo económico. A diferencia de los modelos convencionales, se utiliza un modelo estructuralista-keynesiano para demostrar, teórica y empíricamente, que los factores que influyen en la trayectoria del tipo de cambio real a largo plazo y el distanciamiento del tipo de cambio real observado con respecto al tipo de cambio real "óptimo" para el desarrollo económico se explican, simultáneamente, por variables estructurales y variables influenciadas por la política macroeconómica a corto plazo. Las estimaciones econométricas relativas al período 1999-2015 muestran que, tras una prolongada tendencia de considerable apreciación real desde fines de 2005, el tipo de cambio real en el Brasil alcanzó su nivel "óptimo" a mediados de enero de 2016.
\end{abstract}

\section{Palabras clave}

Desarrollo económico, ajuste estructural, convergencia económica, macroeconomía, tipos de cambio, política monetaria, modelos de desarrollo, modelos econométricos, Brasil

\section{Clasificación JEL}

F30, F32, F39

\section{Autores}

André Nassif es Profesor Adjunto del Departamento de Economía de la Universidad Federal Fluminense, Brasil. Correo electrónico: andrenassif27@gmail.com.

Carmen Feijó es Profesora Titular del Departamento de Economía de la Universidad Federal Fluminense, Brasil. Correo electrónico: cbfeijo@gmail.com.

Eliane Araújo es Profesora Asociada del Departamento de Economía de la Universidad Estadual de Maringá, Brasil. Correo electrónico: elianedearaujo@gmail.com. 



\section{Introducción}

En el Brasil, en el marco de un esfuerzo para construir una macroeconomía estructuralista del desarrollo, el profesor Luiz Carlos Bresser-Pereira ha insistido exhaustivamente en el papel preponderante del tipo de cambio real ${ }^{1}$ en el proceso de desarrollo y convergencia económica (catching up process) ${ }^{2}$ de los países en desarrollo (véase Bresser-Pereira, 2010) ${ }^{3}$. Evidentemente, no se trata de reducir el desarrollo económico - un fenómeno muy complejo en el que influyen no solo fuerzas económicas sino también históricas, sociales y culturales, entre otras - a una sola variable (el tipo de cambio real). Por el contrario, suponiendo que los diversos factores que influyen en el desarrollo actúen a su favor, el referido autor, en un libro recientemente publicado con sus coautores (Bresser-Pereira, Oreiro y Marconi, 2014), argumenta que un proceso de desarrollo se sostiene siempre que el país presente una tasa de inflación estable, una tasa de interés real media inferior a la tasa de rentabilidad real media sobre el capital, una tasa de salarios reales que aumente en consonancia con el incremento de

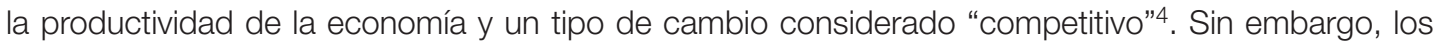
autores destacan que el tipo de cambio real es el precio macroeconómico más importante entre todas esas variables, porque incide en todas las demás (incluida la tasa de inflación). O sea:

Las variables macroeconómicas clave son el déficit en cuenta corriente y el tipo de cambio (...). Las importaciones, las exportaciones, la tasa de inversión, la tasa de ahorro y la inflación dependen del tipo de cambio [real]. Las inversiones también, porque podemos pensar en el tipo de cambio [real] como en el interruptor de la luz que conecta a las empresas eficientes de un país con los mercados externos y con sus propios mercados internos o las desconecta de estos (Bresser-Pereira, Oreiro y Marconi, 2014, págs. 10 y 11).

No es casualidad que, en las experiencias exitosas de los países asiáticos donde ya se logró promover la convergencia económica a los niveles de ingresos per cápita y bienestar de los países desarrollados (en especial la República de Corea, la provincia china de Taiwán y Singapur) y donde todavía se sigue esa estrategia (como China y la India), las monedas nacionales difícilmente estén sobrevaloradas por un largo período de tiempo, como en el caso del Brasil en las últimas décadas ${ }^{5}$.

Curiosamente, en la literatura teórica internacional sobre desarrollo no se atribuye la debida importancia al tipo de cambio real como variable absolutamente estratégica ${ }^{6}$. No obstante, existe

1 En este artículo se define el tipo de cambio como el precio nacional de una unidad de moneda extranjera (por ejemplo, el precio de 1 dólar en reales). Así, un aumento del tipo de cambio conlleva una depreciación de la moneda nacional, mientras que una reducción supone su apreciación.

2 El problema de la convergencia económica, entendida como el emparejamiento de los países pobres a niveles de ingresos per cápita y bienestar similares a los de los países desarrollados, es central en la literatura clásica y neoclásica del desarrollo económico, no obstante los enfoques teóricos de estas dos corrientes sean radicalmente distintos. En el caso de la literatura clásica del desarrollo, véanse Rosenstein-Rodan (1943), Prebisch (1949), Lewis (1954), Myrdal (1957), Hirschman (1961) y Kaldor (1966), entre otros, y, en el de la neoclásica, véanse Solow (1956), Swan (1956), Romer (1986) y Lucas (1988), entre otros.

3 Aunque algunos autores han reconocido su importancia (especialmente Kaldor, 1966 y 1978), la relación entre el tipo de cambio real y el desarrollo económico se ha evaluado en mayor medida mediante trabajos empíricos que análisis teóricos. Como se comenta más adelante, en diversos estudios empíricos recientes se concluyó que, ceteris paribus, los países en proceso de convergencia económica cuyas monedas permanecen ligeramente infravaloradas en términos reales tienden a acelerar el desarrollo económico. Véanse Rodrik (2008), Williamson (2008) y Berg y Miao (2010). Para el caso de los países en desarrollo véanse Gala (2008) y Araújo (2009).

4 Un tipo de cambio "competitivo" es aquel que mantiene la moneda nacional ligeramente infravalorada con respecto al dólar (o a una canasta de monedas) en términos reales. Como se comenta más adelante, la evidencia empírica sugiere que un tipo de cambio "competitivo", ceteris paribus, tiende a acelerar el desarrollo económico.

5 Véanse Amsden (1989 y 2001), Nassif, Feijó y Araújo (2011) para el caso del Brasil y Nassif, Feijó y Araújo (2015a) para los casos de China y la India.

6 Como observa Gala (2008, pág. 273), mientras que la literatura econométrica sobre este tema es relativamente abundante, los análisis teóricos sobre los canales por los cuales el nivel del tipo de cambio real podría afectar el desarrollo económico son muy escasos. 
una vasta literatura empírica en la que se procura evaluar la relación entre la trayectoria del tipo de cambio real y el crecimiento económico a largo plazo. En un gran arsenal de estudios econométricos se concluye que, a menos que se trate del resultado "natural" del aumento de la productividad de los bienes comercializables con respecto a la de los bienes no comercializables (en especial los servicios) - fenómeno que capta el efecto Harrod-Balassa-Samuelson -, la sobrevaloración del tipo de cambio durante períodos prolongados de tiempo en países en desarrollo tiende a reducir el crecimiento económico a largo plazo (Razin y Collins, 1999; Dollar y Kraay, 2003; Prasad, Rajan y Subramanian, 2006; Gala, 2008).

Recientemente, en estudios empíricos más profundos, se mostró que no solo la sobrevaloración del tipo de cambio es perjudicial para el desarrollo económico, sino también que un tipo de cambio real ligeramente superior al tipo de cambio de equilibrio a largo plazo (una pequeña depreciación en términos reales) tiende a acelerarlo. Si bien esa conclusión empírica fue señalada en forma pionera por Rodrik (2008) y confirmada por Berg y Miao (2010), Williamson (2008, pág. 14), un especialista fidedigno en tipo de cambio real, también concluyó que la política óptima (en términos de maximización del crecimiento) es indudablemente una pequeña infravaloración. El énfasis de Williamson en el término "pequeña" no es gratuito, pues - evidentemente- una infravaloración muy acentuada con respecto al tipo de cambio real de equilibrio "neutro", compatible con la paridad real del poder adquisitivo, tiende a reproducir procesos inflacionarios de forma más duradera?

En Nassif, Feijó y Araújo (2011) se propuso una metodología teórica y econométrica de estimación de la trayectoria del tipo de cambio real a largo plazo en las economías en desarrollo. En ese estudio se introdujo el concepto de tipo de cambio real "óptimo" (o "competitivo") a largo plazo - definido como aquel capaz de redirigir de forma eficiente los recursos de la economía hacia las industrias generadoras y difusoras de incrementos de productividad para la economía en general, acelerando y sosteniendo, ceteris paribus, el desarrollo económico- y (hasta donde se sabe, por primera vez en el Brasil) se lo estimó econométricamente. La evidencia empírica indica que dichas industrias corresponden al sector manufacturero, considerado el principal motor dinámico del crecimiento de la productividad, tanto de ese sector como de la economía en su conjunto, como subrayó en forma pionera Kaldor (1966), a partir de la regularidad empírica verificada originalmente por el economista holandés Verdoorn (1949) ${ }^{8}$.

El concepto de tipo de cambio real "óptimo" utilizado se aproxima al de tipo de cambio real de "equilibrio industrial", propuesto por Bresser-Pereira (2010). De acuerdo con ese autor, el tipo de cambio de "equilibrio industrial" sería aquel capaz de mantener a las empresas operando en la vanguardia tecnológica compatible con el sector de actividad productiva al que pertenecen. Pese a las semejanzas, el tipo de cambio de "equilibrio industrial" no es exactamente igual al tipo de cambio real "óptimo" a largo plazo propuesto, pues, al estar ligeramente depreciado en relación con su respectiva trayectoria de equilibrio a largo plazo, este no es necesariamente un tipo de cambio de equilibrio ("industrial", o incluso en relación con el equilibrio "neutro" de la paridad real del poder adquisitivo) ${ }^{9}$. Debido a que no tiene nada que ver con métodos de maximización o tipos de equilibrio, el término "óptimo" en el concepto adoptado aparece siempre entre comillas.

7 Como mostraron Krugman y Taylor (1978), cuando un país corrige en forma abrupta y de una vez una sobrevaloración acentuada (por ejemplo, el Brasil a lo largo de 2015), los efectos inflacionarios y recesivos (porque se reduce el salario real) a corto plazo son inequívocos. Sin embargo, tan pronto como los agentes incorporan ese nuevo equilibrio de precios relativos, ceteris paribus, la tasa de rentabilidad real media sobre el capital empleado en las actividades productivas tiende a aumentar y, en consecuencia, el crecimiento económico y la productividad aumentan y se sostienen a largo plazo.

8 Véase evidencia reciente de esa regularidad empírica (conocida como ley de Verdoorn-Kaldor) en América Latina en Ros (2014).

9 Además, aunque en la estimación del tipo de cambio real de "equilibrio industrial" tampoco se incorporan métodos de maximización, el nivel de depreciación real resultante con respecto al tipo de cambio de equilibrio "neutro" a largo plazo puede ser muy elevado o no. En el concepto de tipo de cambio real "óptimo" propuesto, el nivel de depreciación real es ligeramente superior al del tipo de cambio de equilibrio "neutro" a largo plazo. 
En el artículo se concluyó que el tipo de cambio real habría alcanzado su nivel "óptimo" (el tipo de cambio real a largo plazo estimado econométricamente, no el observado) en 2004 (media del período). En abril de 2011, cuando el tipo de cambio real "óptimo" debería ser de alrededor de 2,90 reales por dólar, en comparación con un nivel observado de apenas 1,59 reales por dólar, había una (mega) sobrevaloración del $82 \%$ con respecto al nivel competitivo necesario para sostener el proceso de desarrollo económico brasileño.

Visto que el real brasileño sufrió una rápida e intensa depreciación nominal a lo largo de 2015, este artículo tiene dos objetivos principales: i) refinar la discusión teórica del modelo estructuralistakeynesiano propuesto, a fin de distinguirlo de los modelos convencionales, tanto en relación con los aspectos teóricos y empíricos vinculados con la trayectoria del tipo de cambio real a largo plazo como con respecto a la desviación del tipo de cambio nominal observado del tipo de cambio real "óptimo" y ii) volver a estimar econométricamente el tipo de cambio real "óptimo" a largo plazo, con miras a determinar si el tipo de cambio nominal observado a inicios de enero de 2016 estaría por encima (infravalorado) o por debajo (sobrevalorado) de ese valor o si sería muy próximo o incluso igual a este. Así, en este trabajo se realiza un análisis crítico de los modelos convencionales de determinación del tipo de cambio real a largo plazo, así como de su nivel de desajuste (sección II), y, a continuación, se discute un modelo teórico estructuralista-keynesiano y se examinan las implicaciones para su estimación empírica (sección III). Por último, se procede a la estimación econométrica de la trayectoria del tipo de cambio real a largo plazo en el Brasil y del nivel considerado "óptimo" para el desarrollo económico (sección IV). El artículo finaliza con una conclusión (sección V).

\section{El modelo convencional de determinación del tipo de cambio real a largo plazo y el nivel de desajuste: un análisis crítico}

La principal teoría sobre el comportamiento del tipo de cambio real a largo plazo ( $R E R$, del inglés real exchange rate) se basa en la hipótesis de la llamada paridad relativa del poder adquisitivo ${ }^{10}$. De acuerdo con esta hipótesis, para que el poder adquisitivo entre dos monedas (expresadas en una misma unidad monetaria común) se mantenga constante a lo largo del tiempo, el tipo de cambio nominal cotizado en el mercado (y expresado como el precio nacional de una unidad de moneda extranjera, por ejemplo el precio de 1 dólar en reales) debe corregirse por la diferencia entre las tasas de inflación nacional e internacional11 ${ }^{11}$ La variación del tipo de cambio real a lo largo del tiempo puede expresarse por:

$$
R E \dot{R}=\dot{e}-\left(\dot{P}-\dot{P}^{*}\right)
$$

en que $R E R$ es el tipo de cambio real; $e$ es el tipo de cambio nominal; $P$ es el nivel de precios interno y $P^{*}$ el nivel de precios externo, por ejemplo de los Estados Unidos. Como los puntos sobre las variables indican tasas instantáneas de variación en el tiempo, la ecuación (1) muestra que el aumento

\footnotetext{
${ }^{10}$ La hipótesis de la paridad real del poder adquisitivo fue desarrollada por Cassel (1918) y, desde entonces, pasó a ser la principal referencia teórica para evaluar el comportamiento del tipo de cambio real a largo plazo (véase, al respecto, Sarno y Taylor, 2002). Sin embargo, la evidencia empírica no confirma la validez de la referida hipótesis en la versión "absoluta" (véase Sarno y Taylor, 2002). A pesar de que la evidencia empírica tampoco es muy robusta con respecto a la validez de la paridad real del poder adquisitivo en su versión "relativa", Rogoff (1996, pág. 647) comenta que la mayoría cree instintivamente en alguna variante de la paridad del poder adquisitivo como ancla para los tipos de cambio reales a largo plazo.

${ }^{11}$ Véase una excelente demostración matemática a partir de la hipótesis de la paridad absoluta del poder adquisitivo en Simonsen y Cysne (1995, págs. 99 y 100).
} 
del tipo de cambio real a lo largo del tiempo (es decir, una depreciación real de la moneda nacional con respecto a la extranjera) debe ser igual al aumento del tipo de cambio nominal (o sea, a la depreciación nominal de la moneda nacional) menos el diferencial entre las tasas de inflación interna y externa.

Esa definición supone que un aumento de $R E R$ o e conlleva una depreciación de la moneda nacional en relación con la extranjera (respectivamente, real y nominal), mientras que una reducción de $R E R$ o e produce una apreciación de la moneda nacional en relación con la extranjera (respectivamente, real y nominal). El principal problema teórico se refiere a la determinación de las fuerzas que supuestamente llevan al tipo de cambio real a un determinado nivel de equilibrio a largo plazo, haciendo que este se iguale, en este caso, al tipo de cambio nominal considerado "neutro" desde el punto de vista competitivo ("neutro" con respecto a los beneficios que pueda significar para los productores nacionales que compiten con las importaciones, los exportadores y los importadores). De acuerdo con la teoría convencional, a excepción de eventuales choques nominales o reales, habría fuerzas "fundamentales" inherentes al propio sistema económico capitalista que llevarían al tipo de cambio nominal a converger a largo plazo hacia su nivel de equilibrio real (Taylor y Taylor, 2004)12. Toda desviación del tipo de cambio real de su nivel de equilibrio "fundamental" sería provocada transitoriamente por choques exógenos imprevistos (Razin y Collins, 1999).

No por casualidad, en las estimaciones empíricas convencionales de la trayectoria del tipo de cambio real y de su nivel de desajuste (infravaloración o sobrevaloración) con respecto al nivel de equilibrio a largo plazo, las dos fuerzas estructurales principales que tienden a influir en el tipo de cambio real en determinado país (es decir, a llevarlo a su nivel de equilibrio "fundamental") son: i) la relación entre la variación de la productividad de los bienes comercializables con respecto a la de los bienes no comercializables y ii) el comportamiento de la relación de intercambio (ToT).

Con respecto a la primera fuerza estructural, una vez que, con el desarrollo económico, la productividad de los bienes comercializables tiende a crecer de forma más acelerada que la de los bienes no comercializables, la reducción de los precios relativos de los primeros en determinado país supone que su moneda tiende a apreciarse "naturalmente". Este es el conocido efecto Harrod-Balassa-Samuelson, según el cual, como recuerdan Obstfeld y Rogoff (1996, cap. 4), los niveles de precios tienden a subir (o sea, el tipo de cambio real tiende a apreciarse) a medida que aumentan los ingresos per cápita de un país ${ }^{13}$.

El efecto esperado de la relación de intercambio en la trayectoria del tipo de cambio real es ambiguo. Baffes, Elbadawi y O’Connell (1999, pág. 413) sostienen (como la mayoría de los autores) que una mejora en la relación de intercambio aumenta los ingresos nacionales medidos en bienes importados; esto provoca un efecto gasto puro que incrementa la demanda de todos los bienes y aprecia el tipo de cambio real. Sin embargo, Edwards (1989) demuestra teóricamente que también puede producirse el efecto contrario: si el aumento de los ingresos derivado de la mejora en la relación de intercambio provoca una marcada sustitución de bienes no comercializables (sobre todo servicios) por bienes comercializables, el incremento de los precios relativos de estos últimos termina llevando a la depreciación de la moneda en términos reales. En otras palabras, según Edwards (1989), el impacto de la mejora en la relación de intercambio en el tipo de cambio real puede ser ambiguo: si prevalece el efecto renta se produce la apreciación de la moneda en términos reales, pero si prevalece el efecto de sustitución se observa su depreciación en términos reales ${ }^{14}$.

\footnotetext{
${ }^{12}$ De acuerdo con Taylor y Taylor (2004), la evidencia empírica muestra que, debido a la rigidez de los precios nominales, las variaciones del tipo de cambio nominal se transmiten de una a una al tipo de cambio real en un plazo muy corto. En otras palabras, una depreciación nominal provoca inmediatamente, y de manera relativamente proporcional, una depreciación real.

${ }^{13} \mathrm{Al}$ traducirse a la forma econométrica, como se verá más adelante, el signo del coeficiente estimado de los ingresos per cápita (variable utilizada para captar el efecto Harrod-Balassa-Samuelson) es negativo, porque el aumento de los ingresos per cápita tiende a reducir (apreciar) el tipo de cambio real.

${ }^{14}$ El signo esperado del coeficiente estimado de la relación de intercambio en la ecuación econométrica de la sección III puede ser negativo, si prevalece el efecto renta, y positivo, si prevalece el efecto de sustitución.
} 
Identificadas las dos principales fuerzas vinculadas con la trayectoria de equilibrio "fundamental" del tipo de cambio real, se procede a las estimaciones econométricas para medir el "desajuste" de los tipos de cambio (es decir, estimar en qué porcentaje el tipo de cambio nominal estaría sobrevalorado o infravalorado con respecto a su valor de equilibrio "fundamental"). En el enfoque convencional se tiende a vincular dicho desajuste con factores, variables y choques aleatorios imprevisibles, pero transitorios ${ }^{15}$. Según ese enfoque, un tipo de cambio real está desajustado cuando se desvía del nivel que prevalecería (es decir, del nivel compatible con los "fundamentos" económicos) en ausencia de rigidez de los precios, fricciones y otros factores a corto plazo, como sostienen Razin y Collins (1999, págs. 59-60). Si bien los modelos se distinguen en cuanto al grado de sofisticación, en las ecuaciones econométricas que procuran medir el grado de desajuste de los tipos de cambio, este se estima básicamente como la desviación del tipo de cambio real observado - que es el estimado, por ejemplo, por el Banco Central del Brasil, sobre la base de índices de tipos de cambio real asociados a la ecuación (1) - de la combinación lineal de un conjunto de variables tomadas como representativas de la trayectoria del tipo de cambio real de equilibrio a largo plazo (y asociadas a precios flexibles, o flex-prices). En la implementación econométrica, tales desviaciones están asociadas, en última instancia, a variables que representan choques a corto plazo más el término que representa el residuo de la regresión (Razin y Collins, 1999, págs. 65-67). En términos formales, en los modelos teóricos convencionales el tipo de cambio real se expresa de la siguiente forma (todas las variables se expresan en logaritmos, excepto la tasa de interés):

$$
R E R_{t}=g_{t}\left(y_{t}^{s}, d_{t}, i^{*}\right)+f_{t}\left(\lambda_{m t}, \lambda_{y t}\right)
$$

en que el tipo de cambio real $R E R$ (todos los subíndices $t$ representan el tiempo $t$ ) está determinado simultáneamente por dos conjuntos de factores: i) el primero, representado por la función $g(. .$.$) ,$ incorpora básicamente variables "fundamentales" que, supuestamente, harían converger el tipo de cambio real hacia su nivel de equilibrio a largo plazo. Por eso, todas las variables contenidas en $g$ son variables reales: $y^{s}$ es el producto real; $d$ es la demanda agregada real e $i^{\star}$ es la tasa de interés real mundial (compatible con la tasa de interés "natural" a largo plazo). Cabe señalar que, en un mundo caracterizado por una competencia perfecta y por la ausencia de cualquier tipo de rigidez de los precios nominales y de choques aleatorios imprevistos, el $R E R$ convergería naturalmente hacia $g(. .$.$) a largo plazo, es decir, sería compatible con el nivel de equilibrio determinado por los$ fundamentos económicos.

Sin embargo, dadas las imperfecciones del mundo real, la teoría convencional atribuye a las variables contenidas en $f(\ldots)$-ya sean choques monetarios (representados por $\lambda_{m}$ ) o reales (representados por $\lambda_{y}$ ) - las causas del desajuste del tipo de cambio real con respecto a su nivel de equilibrio "fundamental" a largo plazo.

Así, para estimar econométricamente la trayectoria del tipo de cambio real a largo plazo, así como el desajuste respecto de su nivel de equilibrio, la ecuación (2) se traduce a la siguiente forma (véase Razin y Collins, 1999, págs. 64-65) ${ }^{16}$.

\footnotetext{
${ }^{15}$ La principal consecuencia normativa de este enfoque, según el cual los choques que desvían el tipo de cambio real de su nivel de equilibrio a largo plazo son transitorios, es que el régimen de cambio más apropiado es el de flotación pura (o casi pura).

${ }^{16}$ Es importante mostrar las representaciones teóricas y econométricas de determinación del tipo de cambio real a largo plazo y el método de estimación del desajuste de los tipos de cambio en los modelos convencionales porque ambos ayudan a delimitar la diferencia radical de esos modelos, no solo con respecto al modelo teórico estructuralista-keynesiano que se propone a continuación, sino también a la metodología de estimación del desajuste aplicada en este trabajo.
} 


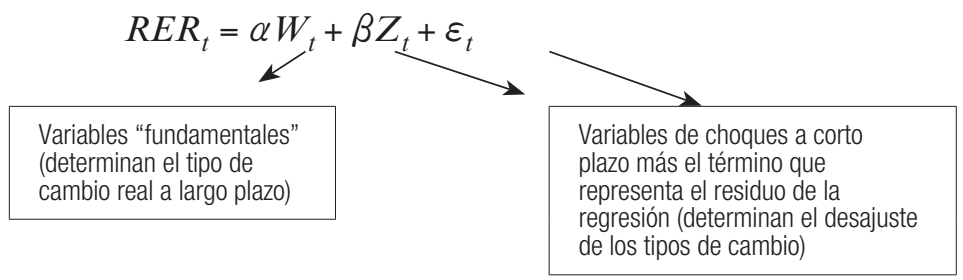

(3)

en que $R E R$ es el tipo de cambio real observado (expresado en logaritmo), $W$ es un conjunto de variables que captan factores de equilibrio "fundamentales" a largo plazo; $Z$ es un conjunto de variables de choques a corto plazo que, junto con el término que representa el residuo $\varepsilon$, explica el desajuste de los tipos de cambio ${ }^{17}$.

\section{La determinación del tipo de cambio real a largo plazo y la desviación del nivel "óptimo" para el desarrollo: un modelo estructuralista-keynesiano}

En esta sección se presenta un modelo estructuralista-keynesiano, en el que la trayectoria del tipo de cambio real a largo plazo y la desviación del tipo de cambio real observado de su nivel de equilibrio "neutro" y de su nivel "óptimo" (como se definió anteriormente) se explican simultáneamente por variables a largo plazo asociadas a la estructura de la economía y por variables directa o indirectamente asociadas a la política macroeconómica a corto plazo (o sea, variables en la esfera de acción de los encargados de la formulación de políticas, ya sea para lidiar con las vicisitudes de los ciclos económicos a corto plazo o para controlar la inflación). En particular, en el modelo estructuralistakeynesiano que se presenta a continuación, la política macroeconómica a corto plazo (especialmente la política monetaria y el régimen de cambio) influye, en gran medida y de forma duradera, en el desajuste del tipo de cambio real observado con respecto a su nivel "óptimo".

En este modelo teórico, tanto la trayectoria del tipo de cambio real a largo plazo como la desviación del tipo de cambio real observado con respecto al nivel "óptimo" pueden representarse mediante la siguiente ecuación:

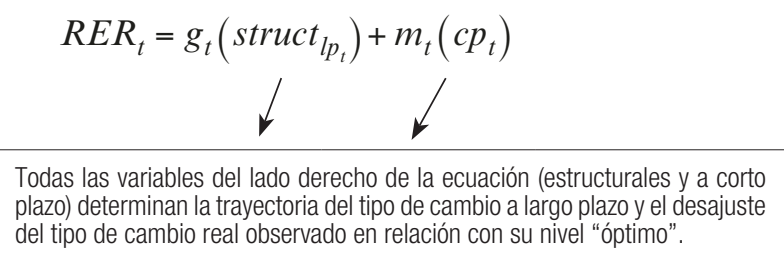

en que el componente $g$ está formado por un conjunto de variables estructurales (struct $t_{l p t}$ ) que influyen en el tipo de cambio real a largo plazo (en especial, los ingresos per cápita $Y$-que capta el efecto Harrod-Balassa-Samuelson, como se señaló anteriormente-, la relación de intercambio To $T$ y los saldos en cuenta corriente de la balanza de pagos $C C$ ), mientras que el componente $m$ se refiere a un conjunto de variables directa o indirectamente influenciadas por la política macroeconómica a corto

\footnotetext{
17 No por casualidad, la estimación del desajuste de los tipos de cambio en los modelos convencionales se expresa por la diferencia entre el lado izquierdo y el primer componente del lado derecho de la ecuación (3).
} 
plazo $\left(c p_{t}\right)^{18}$. En el modelo econométrico propuesto, que se detalla en la próxima sección, las variables a corto plazo relevantes son el diferencial entre las tasas de interés nominales a corto plazo interna $i$ y externa $i^{\star}(I D I F E R)$, el acervo de reservas internacionales $(R I)$ y la prima de riesgo país $(C R)$.

Dos aspectos singulares permiten distinguir el modelo propuesto de los modelos convencionales de determinación del tipo de cambio real a largo plazo. El primero es que, si bien las variables contenidas en el componente $g$ son similares a las que influyen en las variables llamadas "fundamentales" de los modelos convencionales, el modelo propuesto rechaza la hipótesis de que estas siempre hacen converger el tipo de cambio real hacia su nivel de equilibrio a largo plazo. Esto significa que las fuerzas de mercado pueden llevar o no el tipo de cambio real a su nivel "óptimo" a largo plazo, pero si eso ocurre habrá sido a causa del azar o de ajustes del tipo de cambio rápidos e intensos en períodos de crisis (por ejemplo, como ocurrió en el Brasil después del ataque especulativo de 1999 y, más recientemente, como parece haber sido el caso de los acontecimientos de 2015, como muestran los resultados empíricos de la sección IV). Si las fuerzas de mercado no siempre son eficientes para promover el ajuste o evitar desajustes considerables de los tipos de cambio (especialmente sobrevaloraciones), la principal consecuencia normativa es que los encargados de la formulación de políticas deben empeñarse no solo para evitar la volatilidad, sino también para impedir que el tipo de cambio real se desvíe de su nivel "óptimo" o inicie una tendencia de apreciación real. En otras palabras, en lugar de un régimen de flotación pura o sucia, el régimen de cambo más apropiado es el de flotación administrada, que - como mostraron Aizenman, Chinn e lto (2010) - se aplica en la mayoría de los países en desarrollo de Asia.

El segundo aspecto que distingue los dos modelos es que, mientras que en los modelos convencionales solo las variables asociadas a choques a corto plazo son responsables de desajustar el tipo de cambio real con respecto a su nivel de equilibrio a largo plazo, en el modelo estructuralistakeynesiano propuesto todos los componentes del lado derecho de la ecuación (4) pueden explicar simultáneamente el desajuste del tipo de cambio, ya sea con respecto a su nivel de equilibrio o al tipo de cambio real "óptimo" a largo plazo, como se muestra en los cuadros de texto insertados debajo de la referida ecuación.

Esto significa que el procedimiento econométrico propuesto para estimar la desviación del tipo de cambio "óptimo" con respecto al tipo de cambio real observado también difiere de la metodología convencional. Mientras esta última estima la desviación mediante la diferencia entre los tipos de cambio real observados y los tipos de cambio a largo plazo estimados compatibles con el equilibrio "fundamental" (por lo tanto, la desviación estaría influenciada por los coeficientes asociados a las variables de choque a corto plazo más el término de error de la regresión), el procedimiento de cálculo de la desviación propuesto consiste, en primer lugar, en utilizar la técnica del filtro de Hodrick-Prescott para estimar la tendencia a largo plazo de la serie, para luego, tomando la serie de tendencia, elegir un período de referencia (el análisis de los criterios de elección se presenta en la sección IV) para el cálculo de la desviación del tipo de cambio real observado en relación con el tipo de cambio real "óptimo" estimado.

En síntesis, el modelo propuesto se denomina estructuralista porque acepta la hipótesis de que la trayectoria del tipo de cambio real a largo plazo está afectada por variables estructurales, en especial por las variaciones observadas entre los niveles de productividad de los bienes comercializables con respecto a los no comercializables y por la relación de intercambio. Al mismo tiempo, se trata de un modelo keynesiano porque, sobre la base de la propuesta de Keynes (2003, especialmente el cap.12) de que el largo plazo no es más que la suma de acontecimientos que tuvieron lugar en

\footnotetext{
${ }^{18}$ En la forma econométrica, que se presenta en la sección IV, el término que representa el residuo de la regresión se agrega al lado derecho de la ecuación econométrica que representa la ecuación teórica (4) del modelo propuesto. Esto significa que ese término, junto con las variables que representan el componente estructural y de políticas a corto plazo, también influirá en la trayectoria del tipo de cambio real a largo plazo y en la desviación del tipo de cambio real observado con respecto al nivel "óptimo".
} 
sucesivos períodos de corto plazo, se rechaza la hipótesis convencional que distingue tipos de cambio reales de equilibrio a corto y largo plazo ${ }^{19}$. Haciendo un retrato impresionista, eso significa que tanto el nivel como la trayectoria de los tipos de cambio reales a corto y largo plazo son dos caras de la misma moneda ${ }^{20}$.

En efecto, de acuerdo con la teoría keynesiana, los tipos de cambio reales están fuertemente influenciados por flujos netos de capital a corto plazo (Kaltenbrunner, 2008 y 2010), especialmente en una economía caracterizada por una gran apertura financiera global. No es una casualidad que, pese a vivir en un mundo que todavía no estaba dominado por la globalización financiera, Keynes (1923) observara el intenso movimiento de capitales a corto plazo que siguió a la Primera Guerra Mundial y a la caída del patrón oro -inducida, a su vez, por los aumentos defensivos de las tasas de interés a corto plazo en los países del "centro", en especial Inglaterra- y reconociera que dichos flujos financieros en la arena internacional eran el principal mecanismo de transmisión de los diferenciales de interés a corto plazo entre países al tipo de cambio real.

\section{Estimación econométrica de la trayectoria y del nivel "óptimo" del tipo de cambio real a largo plazo}

La especificación econométrica del modelo de determinación de la trayectoria del tipo de cambio real a largo plazo se expresa como:

$$
\begin{gathered}
\ln R_{E} R_{t}=c_{0}+\alpha_{1} \ln Y_{t}+\alpha 2 \ln T o T_{t}+\alpha 3 \ln C C_{t}+ \\
+\beta_{1}(\ln I D I F E R)_{t}+\beta_{2}(\ln I D I F E R)_{t-2}+\beta_{3} \ln R I_{t}+\beta_{4} \ln C R_{t}+\varepsilon_{t}
\end{gathered}
$$

en que (todas las variables del modelo se expresan en logaritmos): $R E R$ es el tipo de cambio real observado; $Y$ es el PIB real per cápita en dólares; ToT es la relación de intercambio; $C C$ es el saldo en cuenta corriente expresado como proporción del $\mathrm{PIB}^{21}$; IDIFER es el diferencial entre la tasa de interés a corto plazo nacional (permuta financiera prefijada a 360 días) y la tasa de interés a corto plazo internacional (tasa objetivo de los fondos federales de los Estados Unidos, tomada como representativa de la tasa de interés a corto plazo externa); $I D I F E R_{t-2}$ es la variable anterior rezagada en dos períodos ${ }^{22} ; R I$ es el acervo de reservas internacionales brasileñas expresadas como proporción del PIB; $C R$ es la prima de riesgo del Brasil, representada por el índice de bonos de mercados emergentes (EMBI) relativo al Brasil de JP Morgan23; $\varepsilon$ es el término de error de la regresión y los

\footnotetext{
19 Véase también Hahn (1984).

20 Por lo tanto, si bien las variables estructurales como la evolución de la productividad y la relación de intercambio continúen entendiéndose como variables a largo plazo, están también fuertemente influenciadas por las políticas económicas a corto plazo. Por eso, nuevamente se insiste en que el largo plazo no es más que el resultado de una sucesión de acontecimientos a corto plazo (influenciados a su vez por políticas económicas a corto plazo).

${ }^{21}$ Conforme Bogdanski, Tombini y Werlang (2000), cuando los saldos en cuenta corriente (CC), presentaron signos negativos se debió agregar un número positivo para poder aplicar la forma logarítmica. En esos casos se adoptó el siguiente procedimiento: $C C=1+C C$.

22 La incorporación del diferencial de interés rezagado en un período en la ecuación econométrica propuesta se justifica porque, dada la tasa de interés externa y suponiendo que todo lo demás permanece constante, un aumento de la tasa de interés interna a corto plazo tiende a estimular la entrada neta de capitales a corto plazo, para posteriormente (es decir, con algún rezago temporal), apreciar la moneda nacional en términos nominales y reales.

${ }^{23}$ La elección del EMBI como medida apropiada para evaluar el riesgo país del Brasil está refrendada por el Banco Central del Brasil (2015), según el cual los indicadores diarios más utilizados en el mercado para esa finalidad (medir el riesgo de crédito de los inversionistas extranjeros en el Brasil) son el EMBI+Br y el Credit Default Swap (CDS, contrato de permuta de riesgo de crédito) del Brasil.
} 
subíndices $t$ son la referencia temporal (en el modelo econométrico propuesto se refiere a un mes). Mientras las tres primeras variables del lado derecho de la ecuación (5) son las variables estructurales (o sea, los ingresos per cápita $Y$, la relación de intercambio $T o T$ y el saldo en cuenta corriente $(C C)$ ), las demás son variables asociadas a la política económica a corto plazo. Las fuentes de la base de datos del análisis, que cubre el período de enero de 1999 a julio de 2015, se describen en el anexo A1.

La elección de las variables del modelo no es arbitraria, pues se observa en gran parte de los modelos de determinación del tipo de cambio real (véanse, por ejemplo, Helmers, 1988; Edwards, 1988; Calvo, Leiderman y Reinhart, 1993; Rodrik, 2008; Berg y Miao, 2010). Sin embargo, cabe subrayar que, aún así, tanto las variables estructurales como las variables de política económica a corto plazo seleccionadas están claramente afinadas con el modelo teórico propuesto. En efecto, en una perspectiva a largo plazo, la evolución de los ingresos per cápita, la relación de intercambio y los saldos en cuenta corriente figuran como las variables estructurales más importantes de un país como el Brasil, cuya estructura productiva y exportadora depende en gran medida de los bienes intensivos en recursos naturales y que ha basado su estrategia de desarrollo en las últimas décadas en la captación de "ahorro externo" (déficits en cuenta corriente) ${ }^{24}$. En una perspectiva a corto plazo, en la literatura keynesiana (véanse Harvey, 2006, y Kaltenbrunner, 2008) se sugiere que las variables de política elegidas (el diferencial de interés, el acervo de reservas internacionales y el riesgo país) son las más relevantes para captar sus efectos directos e indirectos en el tipo de cambio real en una economía sumamente abierta al movimiento de capitales externos, como es el caso del Brasil a lo largo del período analizado.

El modelo propuesto se distingue de los modelos convencionales por el tratamiento teórico y empírico de la determinación del tipo de cambio real a largo plazo y de su nivel de desajuste (en este caso, desajuste con respecto al nivel "óptimo" para el desarrollo económico), como se describió en las secciones anteriores. Antes de proceder a las pruebas estadísticas y a la implementación del modelo econométrico, conviene analizar los signos esperados de los coeficientes estimados de las variables del modelo, que figuran, de forma resumida, en el cuadro 1.

Cuadro 1

Modelo estructuralista-keynesiano de determinación del tipo de cambio real a largo plazo: signos esperados de los coeficientes estimados de las variables del modelo

\begin{tabular}{lc}
\hline Variables del modelo & Signo esperado del coeficiente estimado \\
\hline Ingresos per cápita $(Y)$ & - \\
\hline Relación de intercambio $(T o T)$ & Ambiguo $(+0-)$ \\
\hline Saldo en cuenta corriente $(C C)$ & + \\
\hline Diferencial entre tasas de interés interna y externa $($ IDIFER) & Ambiguo $(+0-$, respectivamente, a cortísimo y corto o medio plazo) \\
\hline Acervo de reservas internacionales $(R I)$ & Ambiguo $(+0-)$ \\
\hline Prima de riesgo país $(C R)$ & + \\
\hline
\end{tabular}

Fuente: Elaboración propia.

Los signos esperados de los coeficientes estimados con respecto a los ingresos per cápita $(Y)$ y a la relación de intercambio (ToT) se justificaron en la sección II. El signo esperado de los coeficientes relacionados con los saldos de la balanza de pagos en cuenta corriente $(C C)$ es positivo, porque - como se señala en la literatura teórica - los saldos tendencialmente superavitarios de

\footnotetext{
${ }^{24}$ Si bien no hay datos desagregados sobre el período más reciente, Nassif (2008, cuadro 1, pág. 87) computaba en 2004 una participación del 40,1\% del valor agregado de los segmentos manufactureros intensivos en recursos naturales en el total del producto manufacturero brasileño (en comparación con el 32,7\% en 1996). Bresser-Pereira, Nassif y Feijó (2016, cuadro 2, pág. 26) calculan que las exportaciones de productos primarios y manufacturados intensivos en recursos naturales (productos básicos) aumentaron al 62,1\% en 2014 (en comparación con el 40,3\% en 2000). Con respecto a la insistencia brasileña en "financiar" su desarrollo mediante entradas netas de "ahorro externo", véanse Bresser-Pereira y Nakano (2003) y BresserPereira, Nassif y Feijó (2016).
} 
esa variable a largo plazo están asociados a una moneda depreciada en términos reales. El signo esperado del coeficiente relativo al diferencial de interés es ambiguo: si bien por una parte, a cortísimo plazo, dada la tasa de interés externa, un aumento de la tasa de interés interna a corto plazo puede depreciar la moneda (signo positivo) por el canal de las expectativas ("temor a la flotación", en este caso "temor de depreciar", como sostienen Calvo y Reinhart, 2002), por otra parte, a corto y mediano plazo, un aumento de la tasa de interés nacional (dada la tasa de interés externa) tiende a, ceteris paribus, estimular las entradas netas de capital y, por consiguiente, a apreciar la moneda en términos reales (signo negativo). El signo del coeficiente esperado de la variable asociada al acervo de reservas internacionales también es ambiguo: el aumento de las reservas externas a lo largo del tiempo significa que el gobierno está haciendo intervenciones de compra en el mercado de cambio a la vista con el fin de, entre otros objetivos, reducir una eventual tendencia de apreciación o incluso inducir una mayor depreciación (signo positivo). Sin embargo, un elevado acervo de reservas puede reducir, ceteris paribus, la prima de riesgo país, estimular de esa manera entradas netas de capital y, en consecuencia, apreciar la moneda nacional en términos reales (signo negativo). Es bien sabido que el signo esperado de la prima de riesgo país es positivo, pues su aumento puede estimular la fuga de capitales y, en consecuencia, la depreciación de la moneda nacional en términos reales (signo positivo).

La primera etapa del análisis empírico fue la implementación de las pruebas de raíz unitaria de Dickey-Fuller aumentada y de Phillips-Perron. Los resultados indican que todas las series son integradas de orden 1, es decir, no estacionarias en nivel pero estacionarias en primera diferencia.

Además de la estacionariedad, es importante considerar también la posibilidad de endogeneidad entre las variables del modelo, porque esta última, al violar la suposición del modelo de mínimos cuadrados ordinarios (MCO) de que el residuo no debe estar correlacionado con las variables explicativas de la regresión, produciría estimadores de MCO sesgados, inconsistentes e ineficientes, comprometiendo el análisis inferencial.

Sin embargo, como mostraron Baffes, Elbadawi y O'Connell (1999, cap. 10), incluso las pruebas de exogeneidad más relevantes, como por ejemplo la propuesta por Engle, Hendry y Richard (1983), no siempre pueden resolver problemas de endogeneidad cuando ocurren cambios en la distribución marginal de las variables explicativas. Aún así, la prueba de cointegración de Johansen (1988) es muy potente para tratar el problema de la endogeneidad en modelos con más de una variable endógena, no solo porque considera como endógenas a todas las variables en el proceso de estimación, sino porque determina simultáneamente la relación de equilibrio entre ellas.

Debido a que las variables no son estacionarias y poseen un mismo orden de integración, es posible emplear la prueba de cointegración propuesta por Johansen (1988) e investigar si existe una relación estable a largo plazo entre ellas. Como la prueba indicó la existencia de un vector de cointegración entre las series, es posible asegurar la existencia de una relación estable a largo plazo entre las variables del modelo 25 .

Al saber que las series son no estacionarias y cointegradas, es posible estimar la ecuación (5) utilizando el método de mínimos cuadrados ordinarios (MCO) y el modelo de vectores de corrección de errores (VEC) ${ }^{26}$. En el cuadro 2 se presentan los resultados del modelo econométrico. Cabe notar que todos los coeficientes estimados fueron estadísticamente significativos y presentaron los signos esperados resumidos en el cuadro 1. Es importante recalcar que mientras el diferencial de interés se incorporó a la ecuación econométrica (5) por razones económicas (véase la nota a pie de

\footnotetext{
25 Los resultados de todas las pruebas descritas en esta sección pueden solicitarse a los autores mediante correo electrónico.

${ }^{26}$ De acuerdo con Hamilton (1994), si las series del modelo poseen esas características, el método de MCO continúa siendo un estimador muy consistente. Véase una demostración formal a este respecto en Hamilton (1994, pág. 587).
} 
página núm. 14), algunas variables del modelo se rezagaron uno o dos períodos (meses) por razones meramente econométricas. En efecto, debido a que las variables seleccionadas son mensuales, es lícito suponer que las variables explicativas estructurales y de política económica no causen efectos en el tipo de cambio real en períodos tan cortos (apenas un mes), de modo que es razonable esperar que el modelo se ajuste mejor a los datos cuando estos se incorporen con algún rezago temporal.

\section{Cuadro 2}

Brasil: modelos estimados del tipo de cambio real a largo plazo, 1999-2015

(Variable dependiente: tipo de cambio real (RER))

\begin{tabular}{|c|c|c|c|c|}
\hline \multirow[b]{2}{*}{ Variable } & \multirow[b]{2}{*}{ Variable } & \multirow{2}{*}{$\begin{array}{c}\text { Coeficiente MCO } \\
\text { (Estadística } t \\
\text { entre corchetes) }\end{array}$} & \multicolumn{2}{|c|}{ Coeficiente VEC } \\
\hline & & & Variable & $\begin{array}{c}\text { (Estadística } t \\
\text { entre corchetes) }\end{array}$ \\
\hline \multirow{2}{*}{$C$} & \multirow{2}{*}{ Constante } & $6,650088^{\star \star \star}$ & \multirow{2}{*}{ C } & $5,9805^{\star \star \star}$ \\
\hline & & {$[10,41783]$} & & \\
\hline \multirow{2}{*}{$\ln Y-2$} & \multirow{2}{*}{ Log del PIB per cápita } & $-0,33637^{\star \star \star}$ & \multirow{2}{*}{$\ln Y-3$} & $-0,763422^{\star \star \star}$ \\
\hline & & {$[-7,61376]$} & & {$[-7,93942]$} \\
\hline \multirow{2}{*}{$\ln T O T$} & \multirow{2}{*}{ Log de la relación de intercambio } & $-0,26492^{\star *}$ & \multirow{2}{*}{$\ln T O T-1$} & $-0,454013^{\star}$ \\
\hline & & {$[-1,91535]$} & & {$[-1,69178]$} \\
\hline \multirow{2}{*}{$\ln C C-1$} & \multirow{2}{*}{ Log del saldo en cuenta corriente/PIB } & $0,068764^{\star \star \star}$ & \multirow{2}{*}{$\ln C C-1$} & $0,085584^{\star \star \star}$ \\
\hline & & {$[4,538101]$} & & {$[2,34562]$} \\
\hline \multirow{2}{*}{$\operatorname{Ln}(I D I F E R)$} & \multirow{2}{*}{ Log del diferencial de interés a corto plazo } & $0,296203^{* *}$ & \multirow{2}{*}{$\operatorname{Ln}(I D I F E R)$} & - \\
\hline & & {$[2,320963]$} & & - \\
\hline \multirow{2}{*}{$\operatorname{Ln}(I D I F E R)-2$} & \multirow{2}{*}{$\begin{array}{l}\text { Log del diferencial de interés } \\
\text { a corto plazo rezagado }\end{array}$} & $-0,24448^{\star *}$ & \multirow{2}{*}{$\operatorname{Ln}(I D I F E R)-2$} & $-0,26921^{\star *}$ \\
\hline & & {$[-2,0114]$} & & {$[-4,41106]$} \\
\hline \multirow{2}{*}{$\ln R I-1$} & \multirow{2}{*}{$\begin{array}{l}\text { Log del acervo de reservas } \\
\text { internacionales/PIB }\end{array}$} & $0,223979^{\star * \star}$ & \multirow{2}{*}{$\ln R I-1$} & $0,167482^{* *}$ \\
\hline & & {$[6,6185]$} & & {$[2,37291]$} \\
\hline \multirow{2}{*}{$\ln C R$} & \multirow{2}{*}{ Log de la prima de riesgo del Brasil } & $0,039893^{*}$ & \multirow{2}{*}{$\ln C R-1$} & $0,372263^{\star \star \star}$ \\
\hline & & {$[1,70786]$} & & {$[5,96244]$} \\
\hline
\end{tabular}

Fuente: Elaboración propia.

Nota: Modelo MCO: R2: 0,839; R2 ajustado: 0,833; estadístico de Durbin-Watson: 1,833; estadístico F: 141,169; Prob (prueba $F$ ): 0,000; número de observaciones: 197 después de los ajustes. La variable IDIFER se incluyó en nivel y con dos rezagos; las variables $C C$ y $R I$ se incluyeron con un rezago y la variable Y con dos rezagos. Modelo VEC: 3 rezagos; número de observaciones: 193 después de los ajustes. Las variables $T O T, C C, R I$ y $C R$ se incluyeron con un rezago; IDIFER con dos rezagos e $Y$ con tres rezagos.

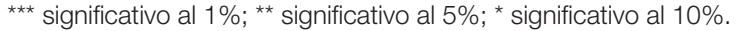

Los resultados muestran que los ingresos per cápita, la relación de intercambio y el diferencial entre las tasas de interés a corto plazo interna y externa fueron las variables cuyos coeficientes estimados presentaron las mayores magnitudes para explicar la trayectoria del tipo de cambio real en el Brasil entre 1999 y 2015. En otras palabras, el modelo econométrico propuesto sugiere que la trayectoria del tipo de cambio real en el Brasil entre enero de 1999 y julio de 2015 - que se mantuvo tendencialmente apreciada en la mayor parte del período, como se muestra en el gráfico 1- fue afectada tanto por variables estructurales de la economía brasileña (como la evolución de los ingresos per cápita, que capta el efecto Harrod-Balassa-Samuelson, y la relación de intercambio, que fue muy favorable al Brasil en gran parte del período analizado), como por variables directamente ligadas a la política macroeconómica a corto plazo (los elevados diferenciales de interés practicados en el Brasil en las últimas décadas estimularon entradas netas excesivas de capitales a corto plazo en los períodos de bonanza económica y elevada liquidez internacional y acabaron por apreciar tendencialmente la moneda brasileña en términos reales) ${ }^{27}$.

\footnotetext{
${ }^{27}$ Cabe señalar que esas dos variables estructurales, los ingresos per cápita y la relación de intercambio, fueron parcialmente responsables de la tendencia a largo plazo de apreciación de la moneda brasileña en términos reales, como se prevé en la teoría económica.
} 
Los coeficientes del modelo econométrico se utilizan para estimar la tendencia a largo plazo del tipo de cambio real (RÊR). Este resultado se compara entonces con el tipo de cambio real observado para construir un índice que permita evaluar si este último está sobrevalorado, infravalorado o en equilibrio con respecto al nivel "óptimo" estimado. Conforme la sugerencia de Edwards (1989) y Alberola (2003), en este estudio se utiliza la técnica del filtro de Hodrick-Prescott para estimar RÊR. En el gráfico 1 se muestran el tipo de cambio real observado (o sea, el $R E R$ divulgado periódicamente por el Banco Central del Brasil, cuya fuente se detalla en el anexo A1) y la trayectoria de los tipos de cambio reales a largo plazo estimados de acuerdo con los dos modelos utilizados (MCO y VEC). Tanto los tipos de cambio reales observados como los estimados están, por ahora, expresados en logaritmos.

\section{Gráfico 1}

Brasil: tipos de cambio reales observados y tipos de cambio reales a largo plazo estimados, enero de 1999 a julio de 2015

(En logaritmos)

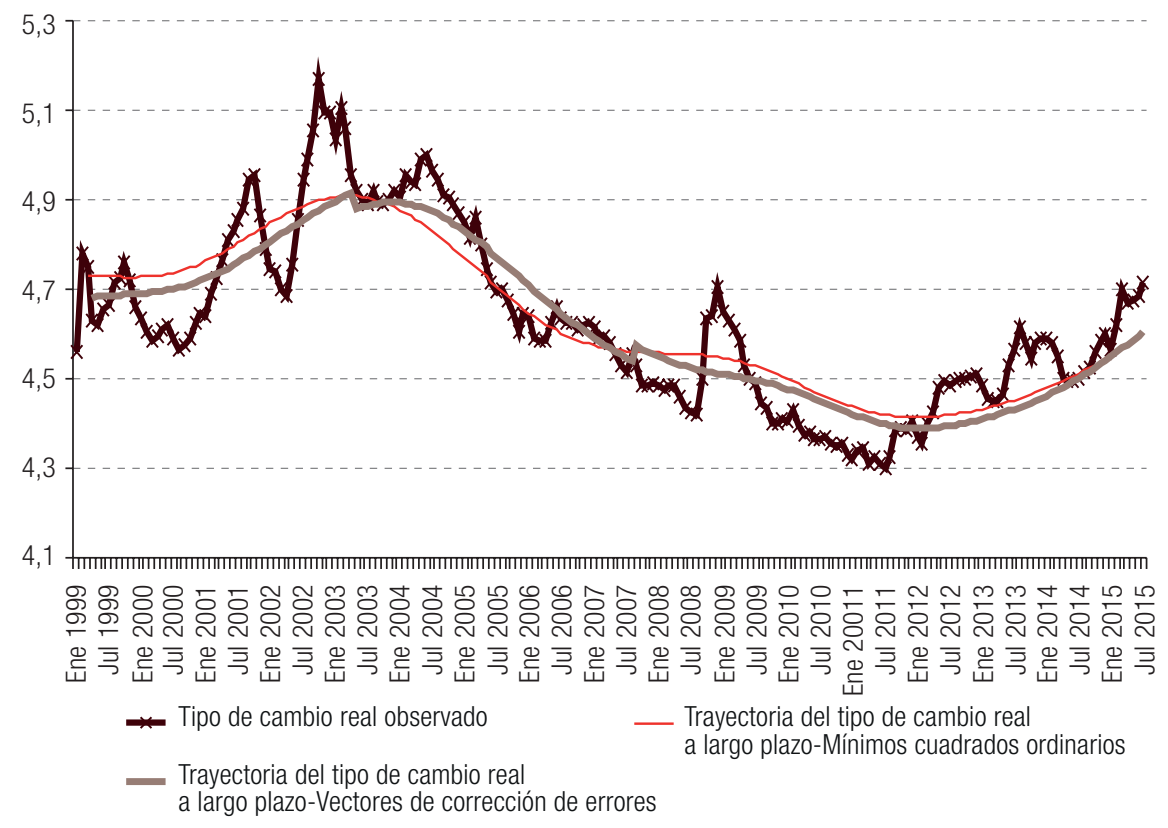

Fuente: Elaboración propia.

Los resultados robustos de las estimaciones pueden confirmarse no solo por el nivel de significación de los coeficientes estimados (detallados en el cuadro 2), sino también por la superposición de las trayectorias de los tipos de cambio estimados con los dos modelos de estimación, que indica resultados bastante similares, tanto en la estimación por MCO como en la estimación por VEC. También cabe señalar la elevada correlación entre las trayectorias de los tipos de cambio estimados (en los dos modelos) y las de los tipos de cambio reales observados. Los dos modelos estimados sugieren que el tipo de cambio real en el Brasil comenzó una trayectoria de apreciación entre fines de 2003 el inicios de 2004, no obstante en ese último año el tipo de cambio real observado todavía registrara un nivel de infravaloración significativo, como puede apreciarse en el gráfico 2.

El gráfico 2 permite comparar las trayectorias de los tipos de cambio reales observados con los tipos de cambio reales a largo plazo estimados según los dos modelos (MCO y VEC). 


\section{Gráfico 2}

Brasil: tipos de cambio reales observados y niveles de infravaloración o sobrevaloración con respecto a los tipos de cambio reales estimados, enero de 1999 a julio de 2015

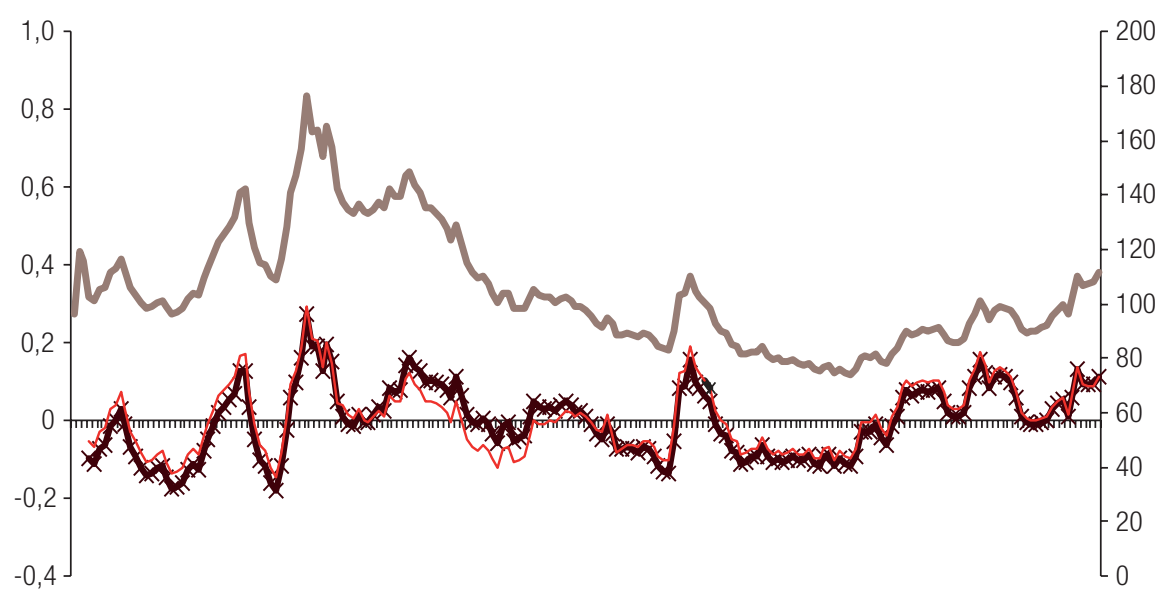

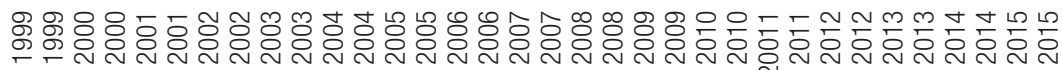

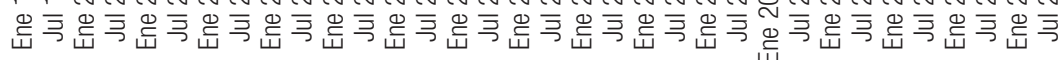

* Tipo de cambio real observado-Trayectoria del tipo de cambio real a largo plazo-Mínimos cuadrados ordinarios

— Tipo de cambio real observado-Trayectoria del tipo de cambio real a largo plazo-Vectores de corrección de errores

- Tipo de cambio real observado

Fuente: Elaboración propia, sobre la base de la metodología descrita, para los tipos de cambio reales estimados, y Banco Central del Brasil, para los tipos de cambio reales observados (véase el anexo A1).

Nota: i) Los tipos de cambio reales observados (representados en las líneas superiores del gráfico) están expresados en números índices indicados en el eje vertical derecho (media de 2000=100): un valor superior a 100 indica infravaloración del real con respecto al año base, mientras que un valor inferior a 100 indica sobrevaloración con respecto al mismo año base (media de 2000).

ii) Los porcentajes de infravaloración y sobrevaloración (representados en las líneas inferiores del gráfico) se calcularon como la diferencia entre el tipo de cambio real observado (RER) y las tendencias a largo plazo de los tipos de cambio reales estimados por los dos modelos (RÊR). Si este resultado es superior a 0, existe una infravaloración estimada del real brasileño, mientras que si es inferior a 0, existe una sobrevaloración estimada. Estos resultados, expresados en porcentajes, se indican en el eje vertical izquierdo del gráfico.

En lo que se refiere a los tipos de cambio reales a largo plazo estimados por ambos modelos (indicados mediante las dos líneas superpuestas en la parte inferior del gráfico 2), los resultados inferiores a 0,00 indican sobrevaloración (en porcentajes) de los tipos de cambio observados con respecto a los tipos de cambio reales estimados, mientras que los resultados superiores a 0,00 indican infravaloración con respecto a estos. En cuanto al tipo de cambio real observado $(R E R$, indicado por la línea punteada en la parte superior del gráfico 2), los índices por debajo de 100 significan sobrevaloración con respecto a la media de 2000 (que es, por hipótesis, igual a 100, y corresponde al año en que se supone que el tipo de cambio real observado estaría en equilibrio, de acuerdo con el Banco Central del Brasil), mientras que los índices por encima de 100 denotan infravaloración con respecto a la media de 2000.

Una vez estimada la trayectoria de los tipos de cambio reales de acuerdo con los dos modelos, cabe finalmente describir la metodología para la determinación del tipo de cambio real "óptimo". Esto se lleva a cabo estableciendo el período en que el tipo de cambio real en el Brasil habría alcanzado su nivel "óptimo" para el desarrollo económico, de acuerdo con el concepto presentado al comienzo de este artículo. Una vez establecido ese período, es posible finalmente concluir si el tipo de cambio nominal medio vigente en la primera quincena de enero de 2016 (fase de conclusión de este trabajo) estaría sobrevalorado, infravalorado o sería igual a su nivel "óptimo". 
El criterio para la elección del período en que el tipo de cambio real alcanzó el nivel "óptimo" para el desarrollo económico del Brasil contemporáneo debe cumplir con tres condiciones simultáneas: i) en consonancia con los estudios empíricos recientes mencionados, según los cuales la moneda nacional de un país en desarrollo debe estar ligeramente infravalorada (o sea, debe presentar una pequeña desvalorización real con respecto al dólar estadounidense o a una canasta de monedas de los principales socios comerciales externos), el período elegido debe corresponder a una fase en que el tipo de cambio estimado (no el observado) esté un poco (pero no muy) infravalorado (apenas por encima de 0,00 en el gráfico 2$)^{28}$, ii) el período elegido debe corresponder a una fase en que los indicadores macroeconómicos sean relativamente sólidos, especialmente con respecto al saldo en cuenta corriente, que debe estar equilibrado o ser superavitario y iii) el período elegido debe estar comprendido en una fase en que el tipo de cambio real observado no esté sobrevalorado (el índice no debe estar por debajo de 100 en el gráfico 2).

Siguiendo el criterio propuesto, es necesario descartar todos los períodos en que los tipos de cambio reales estimados u observados estuvieran sobrevalorados (enero de 2010 a enero de 2012, solo para citar un ejemplo ${ }^{29}$. Asimismo deben descartarse los períodos en que el tipo de cambio real estimado haya estado excesivamente infravalorado, como, por ejemplo, el período entre abril de 2002 y abril de 2003 (pues las depreciaciones excesivas del tipo de cambio pueden tener efectos más permanentes en la inflación) ${ }^{30}$. El período de abril de 2012 a abril de 2013 también debe descartarse porque, si bien el tipo de cambio estimado presentaba una pequeña infravaloración (media del 7\% en el período, de acuerdo con los dos modelos estimados) - satisfaciendo la primera condición - el tipo de cambio real observado estaba sobrevalorado (índice de cambio real medio de 95,70) y los indicadores macroeconómicos del país mostraban signos de deterioro aún mayores ${ }^{31}$.

Una inspección más detallada del gráfico 2 permite concluir que el tipo de cambio real "óptimo" se alcanzó en algún momento entre junio de 2003 y abril de 2005, el único período que cumple simultáneamente con las tres condiciones señaladas. En esa fase la economía brasileña se encontraba en el proceso final de ajuste macroeconómico que se estaba implementando desde mediados de 1999 y presentaba tasas de crecimiento más altas y saldos superavitarios en cuenta corriente ${ }^{32}$. Además, el tipo de cambio real medio estimado según los dos modelos indicaba una pequeña infravaloración del 5,05\% y, por último, el índice del tipo de cambio real medio observado no presentaba ningún

${ }^{28}$ Barbosa-Filho y otros (2010) afirman que un modelo teórico estructuralista y la evidencia del Brasil (1996-2009) sugieren que existe un nivel de tipo de cambio óptimo que maximiza el crecimiento. En su estudio, los autores estiman que el índice de tipo de cambio real que maximizaría el crecimiento económico brasileño a largo plazo seria de alrededor de 101,6, o sea, una depreciación real (en el margen) de alrededor del 1,6\% con respecto al tipo de cambio real "neutro". Un tipo de cambio real que introdujera una depreciación real muy elevada podría ser, evidentemente, refractario al crecimiento a largo plazo, ya sea porque produciría un efecto inflacionario más permanente o porque causaría una distorsión mucho más acentuada y menos deseada en la asignación de los recursos productivos en la economía.

29 En ese período, los tipos de cambio reales estimados indicaron una sobrevaloración de alrededor del 7,8\% (media de los dos modelos), el índice del tipo de cambio real observado (RER) equivalía a 81,67 (que indica una sobrevaloración del real brasileño de cerca del 18,3\% con respecto a la media de 2000) y los indicadores macroeconómicos eran mucho menos sólidos que, por ejemplo, en 2007. En efecto, al considerar solo 2011 y para citar apenas dos indicadores, de acuerdo con el Banco Central del Brasil, la tasa de variación del PIB real fue del 3,9\% (en comparación con el 6,1\% en 2007) y el déficit en cuenta corriente alcanzaba casi el 2,1\% del PIB (en comparación con un superávit del 0,1\% en 2007).

30 El modelo propuesto indica una infravaloración media estimada de cerca del 11\% (media de los dos modelos) entre abril de 2002 y abril de 2003, considerada muy excesiva.

${ }^{31}$ En 2013, de acuerdo con la base de datos del Banco Central del Brasil, la tasa de variación del PIB real fue del 3\% y el saldo en cuenta corriente alcanzó un resultado negativo equivalente al 3,6\% del PIB.

32 En 2004, por ejemplo, según la base de datos del Banco Central del Brasil, la tasa de variación del PIB real fue del 5,8\% y el saldo en cuenta corriente registraba un superávit del 1,8\% como proporción del PIB. 
indicio de sobrevaloración ${ }^{33}$. Así, considerando el período entre junio de 2003 y abril de 2005 como el punto de referencia en que el tipo de cambio real habría alcanzado su nivel "óptimo", la media del índice estimado del tipo de cambio real a largo plazo fue de 127,82 (MCO: 125,87 y VEC: 129,87). Al comparar este último índice estimado con el índice del tipo de cambio real observado en julio de 2015 -último mes en que había datos disponibles para todas las variables del modelo - (correspondiente a 111,81), se puede concluir que, en ese último mes, el real brasileño presentaba una sobrevaloración real de cerca del 14,36\% con respecto a su nivel "óptimo" a largo plazo. O sea, en julio de 2015, el tipo de cambio nominal medio debería haber sido de cerca de 3,88 reales por dólar (en comparación con un tipo nominal medio observado de 3,39 reales por dólar) para preservar el nivel "óptimo" alcanzado entre junio de 2003 y abril de 2005.

Si bien los datos disponibles permitieron que la estimación econométrica llegara solo hasta fines de julio de 2015, es posible ajustar este último dato hasta diciembre de 2015, sobre la base de la hipótesis de la paridad relativa real del poder adquisitivo ${ }^{34}$. Al disponer de datos sobre los índices de precios al consumidor en el Brasil y los Estados Unidos (respectivamente, el índice nacional de precios al consumidor en su concepto amplio (IPCA) y el CPI) hasta diciembre de 2015, sobre la base de la diferencia entre las tasas de inflación acumuladas en el Brasil y los Estados Unidos entre agosto y diciembre de ese año (IPCA: 3,6\%; CPI: -0,1\%), se puede concluir que el tipo de cambio real "óptimo" en diciembre de 2015 debería ser de alrededor de 4,02 reales por dólar ${ }^{35}$. Este resultado es bastante similar al tipo de cambio nominal medio de ese mes (3,90 reales por dólar) y exactamente igual a la media de la primera quincena de enero de 2016 (4,02 reales por dólar), como consta en el sitio web del Banco Central del Brasil. En síntesis, después de un largo ciclo de considerable apreciación real desde fines de 2005 (interrumpido apenas por unos seis meses inmediatamente después del estallido de la crisis financiera mundial de septiembre de 2008), el tipo de cambio real en el Brasil alcanzó su nivel "óptimo" a mediados de enero de 2016.

Se entiende que, para poder deducir si el tipo de cambio nominal que prevalecerá en el Brasil en un período de tiempo relativamente corto (como máximo, en los próximos dos años, o sea hasta fines de 2017) estará sobrevalorado, infravalorado o será equivalente a su nivel "óptimo", el tipo de cambio real "óptimo" alcanzado en diciembre de 2015 podrá ajustarse mediante el mismo procedimiento anterior (o sea, por la diferencia acumulada entre la inflación brasileña y la internacional). En el caso de períodos más largos, considerando que la trayectoria del tipo de cambio real está fuertemente afectada por variables estructurales y por la propia política económica, se sugiere volver a estimar los modelos de determinación del tipo de cambio real "óptimo" como el aquí propuesto (o similares, como el propuesto por Marconi, 2012).

\footnotetext{
${ }^{33}$ Con respecto al tipo de cambio real observado, el índice medio en el período fue de 135,52, que indica una infravaloración del real de cerca del 35,5\% con respecto a la media de 2000. Un analista podría alegar que el período no podría considerarse como aquel en que el tipo de cambio real habría alcanzado su nivel "óptimo", debido a la excesiva infravaloración real de la moneda. Sin embargo, esta crítica sería errónea por dos razones: la primera, porque se trata del tipo de cambio real observado, cuyos índices se construyen solo sobre la base de los diferenciales de inflación interna y externa (y, tratándose del tipo de cambio real efectivo, ponderados por el peso relativo de cada socio comercial del Brasil en la construcción del referido índice) y, la segunda (y, tal vez más importante), como se puede observar en el gráfico 2, la moneda brasileña estaba eliminando la excesiva infravaloración desde octubre de 2002, año en que se registró un claro reajuste excesivo del tipo de cambio real-dólar. Como bien observó Barbosa-Filho (2015, pág. 405), el período 2003-2005 correspondió a la fase de "corrección cambiaria", porque fue la etapa durante la cual la apreciación del real brasileño básicamente eliminó la depreciación rápida y sustancial que tuvo lugar en los años anteriores.

${ }^{34}$ Como se analizó anteriormente, de acuerdo con la hipótesis de la paridad relativa real del poder adquisitivo, para preservar el nivel real del poder adquisitivo de la moneda, el tipo de cambio nominal debe corregirse por la diferencia entre las tasas de inflación acumuladas interna y externa.

35 Los datos relativos al Brasil se tomaron del Instituto Brasileño de Geografía y Estadística (IBGE) y los de los Estados Unidos de la Oficina de Estadísticas Laborales de ese país. Para el IBGE, véase [en línea] http://www.ibge.gov.br/home/estatistica/ indicadores/precos/inpc_ipca/defaultinpc.shtm. Para los Estados Unidos, véase [en línea] http://www.bls.gov/cpi/. [Fecha de consulta: 20 de enero de 2015].
} 


\section{Conclusión}

Durante el reciente ciclo de sobrevaloración del real brasileño, que tuvo lugar entre mediados de 2005 y fines de 2014 y se interrumpió temporáneamente solo en los seis meses posteriores al estallido de la crisis financiera mundial de septiembre de 2008, el ex ministro de Hacienda Guido Mantega quiso atribuir dicha tendencia a factores externos - en especial a la política de flexibilización cuantitativa de los Estados Unidos, que provocó una enorme expansión de la liquidez en dólares en los mercados mundiales, forzando, a su juicio, la apreciación de las monedas de los países emergentes, en particular el real brasileño - acusó al Banco de la Reserva Federal de los Estados Unidos de propagar una "guerra cambiaria".

En un artículo preparado para la tradicional Mundell-Fleming Lecture, promovida anualmente por el Fondo Monetario Internacional (FMI), Ben Bernanke (2015), ex-Presidente del Banco de la Reserva Federal de los Estados Unidos, mostró que las acusaciones de Mantega eran teórica y empíricamente infundadas. Aunque escapa al alcance de este artículo detallar las críticas de Bernanke, la principal se refiere a que, según el autor (2015, pág. 4), los encargados de la formulación de políticas extranjeros [en este caso, brasileños] están constreñidos principalmente por las limitaciones de la "trinidad imposible" inherente al modelo Mundell-Fleming - la imposibilidad de combinar el libre flujo de capitales, una política monetaria independiente y objetivos de tipo de cambio- y no por la política estadounidense en sí.

Sin embargo, el propio Bernanke (2015, pág. 4) advierte más adelante que las políticas monetaria y cambiaria deberían priorizar determinados objetivos macroeconómicos, de manera que el problema de los efectos indirectos [de la política monetaria estadounidense en los flujos internacionales de capital] se aborde mediante medidas regulatorias y macroprudenciales, que posiblemente incluyan controles de capital dirigidos, y una cuidadosa secuencia de reformas de mercado. No por casualidad, como argumentó recientemente Hey (2015, pág. 1) en un artículo de enorme repercusión académica, el ciclo financiero global transforma la "trinidad imposible" en un dilema o "dúo irreconciliable": las políticas monetarias independientes son posibles si y solo si se administra la cuenta de capital.

Las críticas de Bernanke son pertinentes porque, como ya habían demostrado Aizenman, Chinn e Ito (2010), en la mayoría de los países asiáticos se procura evitar prolongados ciclos de apreciación crónica de las monedas en términos reales implementando medidas que apuntan a superar las limitaciones impuestas por la "trinidad imposible". Según los autores, después de las desastrosas consecuencias de la crisis asiática de 1997 - cuyos orígenes estarían ligados al período anterior en que las elevadas entradas netas de capitales externos produjeron una enorme sobrevaloración de las monedas -, los encargados de la formulación de políticas de la mayoría de los países de la región han procurado mantener la estabilidad monetaria y cambiaria, evitando la volatilidad y sobre todo la tendencia cíclica y crónica a la apreciación. Para ello utilizan una combinación de instrumentos disponibles, que incluyen intervenciones en los mercados al contado y de futuros, medidas regulatorias y macroprudenciales y controles de capitales ad hoc ${ }^{36}$. A propósito, el recurso al instrumento de control de capitales, hasta hace no mucho tiempo considerado una herejía por las instituciones multilaterales de crédito, ha sido defendido recientemente por el FMl en documentos oficiales (véanse los estudios de Ostry y otros, 2011; Ostry, Ghosh y Chamon, 2012). Se sugiere que los encargados de la formulación de políticas brasileños sigan el ejemplo asiático y utilicen, de forma prudente y eficiente, el menú de instrumentos de política cambiaria disponibles para evitar un nuevo ciclo prolongado de apreciación crónica de la moneda brasileña en términos reales.

Al comienzo de este artículo se resaltó el papel estratégico del tipo de cambio real ligeramente infravalorado en la promoción del cambio estructural, el desarrollo y la convergencia económica.

36 Véanse Aizenman, Chinn e Ito (2010), para el caso general del continente asiático, y Subbarao (2014), para el caso de la India. 
En cuanto a esos resultados esperados, es preciso advertir, sin embargo, que incluso en la hipótesis de que en los próximos años se consiga preservar el nivel "óptimo" del tipo de cambio real alcanzado en enero de 2016, no será fácil recuperar el enorme atraso tecnológico acumulado por la industria brasileña con respecto a la frontera tecnológica internacional, condición sine qua non para sostener niveles más elevados de productividad, no solo en este sector, sino en la economía en general ${ }^{37}$. Cabe recordar que esta conclusión está relacionada con la evidencia empírica de que el sector manufacturero es el principal motor dinámico del crecimiento de la productividad, tanto de ese sector como de la economía en su conjunto, como subrayó en forma pionera Kaldor (1966), a partir de la regularidad empírica verificada originalmente por el economista holandés Verdoorn (1949) ${ }^{38}$.

Sin embargo, en virtud de la marcada regresión industrial y de la reprimarización de la pauta exportadora brasileña en las últimas décadas ${ }^{39}$, el desarrollo tecnológico, debido a sus características indisociables y fuertemente dependientes de la trayectoria, podrá quedar "trabado" durante un largo período, hasta que las políticas industriales y tecnológicas, en coordinación con la política macroeconómica, consigan eliminar la histéresis derivada de décadas de tasas de interés reales elevadas (elevado costo del capital) y apreciación cíclica y crónica de la moneda brasileña en términos reales ${ }^{40}$. Como argumentan Baldwin y Krugman (1989, pág. 653) en su artículo clásico, si ya era un gran error ignorar la realimentación entre los flujos de comercio y el tipo de cambio real, es igualmente erróneo ignorar la realimentación entre este último y el costo del capital. Según los autores, una depreciación correctiva de la sobrevaloración acumulada en el pasado puede restaurar los saldos de la balanza comercial, pero no recuperar mercados perdidos o agregar nuevos mercados (ibíd., pág. 637). Asimismo afirman que los economistas ya tendrían que haber incorporado la noción de histéresis en la teoría económica (ibíd., pág. 25).

Como mostró Krugman (1991, pág. 652) en otro artículo seminal, en la existencia de rendimientos crecientes estáticos y dinámicos de escala, una economía que se atrasó durante décadas y retrocedió con respecto a la frontera tecnológica internacional presenta una enorme posibilidad de que su reorientación a diversos puntos de equilibrio múltiples se resuelva, en parte, por la historia, es decir, una situación en que los acontecimientos pasados comienzan a dictar las precondiciones que la llevan hacia otro punto de equilibrio estable (ya sea este positivo o negativo).

Por esa razón, aunque sea poco probable que el ajuste del tipo de cambio real a su nivel "óptimo" sea por sí mismo capaz de revertir, de inmediato, la trayectoria actual de retraso relativo de la economía brasileña, reorientándola hacia un nuevo proceso de convergencia económica, al tratarse de un precio estratégico relevante para hacer cumplir tal objetivo, dicho ajuste cambiario tendrá una parte considerable de responsabilidad ${ }^{41}$. Es justamente por eso que se hace hincapié en la sugerencia de que los encargados de formular políticas brasileños consideren al tipo de cambio real en el Brasil como un precio estratégico relevante para el desarrollo económico y no como un ancla eterna para mantener la estabilidad inflacionaria.

\footnotetext{
${ }^{37}$ De acuerdo con Nassif, Feijó y Araújo (2015a), la brecha (distancia relativa) de productividad del trabajo de la industria manufacturera brasileña con respecto a la estadounidense (representativa de la frontera tecnológica internacional) aumentó del $70 \%$ al $80 \%$ entre 1980 y 2000 y se mantuvo en ese último nivel hasta 2013.

${ }^{38}$ Véase evidencia reciente de esa regularidad empírica (conocida como ley de Verdoorn-Kaldor) en América Latina en Ros (2014).

39 La pérdida de participación de la industria de transformación brasileña (en valor agregado) en el PIB (en términos reales) ha sido dramática en las últimas décadas: del 21,6\% en 1980 disminuyó al 18,1\% en 1990, el 15,1\% en 2000, el 13,9\% en 2010 y el 11,7\% en el primer semestre de 2015. La reprimarización de la pauta exportadora, como se señaló anteriormente, puede constatarse por el aumento de la participación de los productos agropecuarios y los bienes industrializados intensivos en recursos naturales (productos básicos) en el total exportado, del 40,3\% al 62,5\% entre 2000 y 2014. Véase Bresser-Pereira, Nassif y Feijó (2016).

40 La noción de histéresis, un fenómeno de la física incorporado en forma pionera a la teoría económica por Blanchard y Summers (1986), se refiere a la situación en que determinado material (en este caso, la competitividad de la industria brasileña) tiene gran dificultad para recuperar sus características originales (las elevadas tasas de incremento de la productividad), incluso después de haberse eliminado la principal fuente causadora de dicha perturbación (en este caso, la enorme sobrevaloración del tipo de cambio).

41 Véase evidencia empírica del rezago de la economía brasileña en Nassif, Feijó y Araújo (2015b).
} 


\section{Bibliografía}

Aizenman, J., M. D. Chinn y H. Ito (2010), "Surfing the waves of globalization: Asia and financial globalization in the context of the trilemma", La Follette School Working Paper, N²010-009, Madison, La Follette School of Public Affairs.

Alberola, E. (2003), "Misalignment, liabilities dollarization and exchange rate adjustment in Latin America", Working Papers, № 309, Banco de España.

Amsden, A. H. (2001), The Rise of "the Rest": Challenges to the West from Late-Industrializing Economies, Oxford, Oxford University Press. (1989), Asia's Next Giant: South Korea and Late Industrialization, Oxford, Oxford University Press.

Araújo, E. (2009), "Política cambial e crescimento econômico: teorias e evidências para os países em desenvolvimento e emergentes", tesis, Río de Janeiro, Instituto de Economía, Universidad Federal de Río de Janeiro.

Baffes, J., I. Elbadawi y S. A. O'Connell (1999), "Single-equation estimation of the equilibrium real exchange rate", Exchange Rate Misalignment: Concepts and Measurement for Developing Countries, L. E. Hinkle y P. J. Montiel (eds.), Oxford University Press.

Baldwin, R. y P. R. Krugman (1989), "Persistent trade effects of large exchange rate shocks", The Quarterly Journal of Economics, vol. 104, № 4, Oxford, Oxford University Press.

Banco Central del Brasil (2015), "Risco-país: com informações até março de 2015", Brasilia [en línea] http:// www4.bcb.gov.br/pec/gci/port/focus/faq\%209-risco\%20pa\%C3\%ADs.pdf.

Barbosa-Filho, N. (2015), "O desafio macroeconômico de 2015-2018", Revista de Economia Política, vol. 35, $N^{\circ}$ 3, São Paulo.

Barbosa-Filho, N. y otros (2010), "Real Exchange Rate, Capital Accumulation and Growth in Brazil" [en línea] http://eesp.fgv.br/sites/eesp.fgv.br/files/file/4c0d022668198.pdf.

Berg, A. e Y. Miao (2010), "The real exchange rate and growth revisited: the Washington Consensus strikes back?", IMF Working Paper, № 10/58, Washington, D.C., Fondo Monetario Internacional (FMI).

Bernanke, B. (2015), "Federal reserve policy in an international context", documento presentado en la 16th Jacques Polak Annual Research Conference, Washington, D.C., 5 y 6 de noviembre [en línea] https:// www.imf.org/external/np/res/seminars/2015/arc/pdf/Bernanke.pdf.

Blanchard, O. y L. H. Summers (1986), "Hysteresis and the European unemployment problem", NBER Working Paper, № 1950, Cambridge, Massachusetts, Oficina Nacional de Investigaciones Económicas.

Bogdanski, J., A. Tombini y S. R. C. Werlang (2000), "Implementing inflation targeting in Brazil", Working Papers series, № 1, Brasilia, Banco Central del Brasil [en línea] https://www.bcb.gov.br/pec/wps/ingl/wps01.pdf.

Bresser-Pereira, L. C. (2010), Globalização e competição: por que alguns países emergentes têm sucesso e outros não, Río de Janeiro, Ed. Campus.

Bresser-Pereira, L. C. e Y. Nakano (2003), "Crescimento econômico com poupança externa?", Revista de Economia Política, vol. 23, № 2, São Paulo.

Bresser-Pereira, L. C., A. Nassif y C. Feijó (2016), "The Case for Reindustrializing the Brazilian Economy: Connecting the Macroeconomic Regime and the Industrial Policy", documento preparado para la $13^{a}$ Conferencia Internacional "Developments in Economic Theory and Policy", Bilbao, 23 y 24 de junio.

Bresser-Pereira, L. C., J. L. Oreiro y N. Marconi (2014), Developmental Macroeconomics: New Developmentalism as a Growth Strategy, Londres, Routledge.

Calvo, G. y C. Reinhart (2002), "Fear of floating", Quarterly Journal of Economics, vol. 117, № 2, Oxford, Oxford University Press.

Calvo, G., L. Leiderman y C. Reinhart (1993), "Capital inflows and real exchange rate appreciation in Latin America. The role of external factors", IMF Staff Papers, vol. 40, № 1, Washington, D.C., Fondo Monetario Internacional (FMI).

Cassel, G. (1918), "Abnormal deviations in international exchanges", Economic Journal, vol. 28, № 112, Wiley.

Dollar, D. y A. Kraay (2003), "Institutions, trade and growth", Journal of Monetary Economics, vol. 50, № 1, Amsterdam, Elsevier.

Edwards, S. (1989), Real Exchange Rates, Devaluation, and Adjustment: Exchange Rate Policy in Developing Countries, Cambridge, Massachusetts, The MIT Press.

(1988), "Real and monetary determinants of real exchange rate behavior: theory and evidence from developing countries", UCLA Working Paper, N 506, Los Ángeles, Universidad de California. 
Engle, R. F., D. F. Hendry y J. F. Richard (1983), "Exogeneity", Econometrica, vol. 51, № 2, Nueva York, Econometric Society.

Gala, P. (2008), "Real exchange rate levels and economic development: theoretical analysis and econometric evidence", Cambridge Journal of Economics, vol. 32, № 2, Oxford University Press.

Hahn, F. (1984), "Die Allgemeine Gleichgewichtstheorie", Die Krise der Wirtschaftstheorie, D. Bell e I. Bristol (eds.), Berlín, Springer Verlag.

Hamilton, J. D. (1994), Time Series Analysis, Princeton, Princeton University Press.

Harvey, J. T. (2006), "Modeling interest rate parity: a system dynamics approach", Journal of Economic Issues, vol. 40, № 2, Taylor and Francis.

Helmers, F. L. C. H. (1988), "The real exchange rate", The Open Economy: Tools for Policymakers in Developing Countries, R. Dornbusch y F. L. C. H. Helmers (eds.), Oxford, Oxford University Press.

Hey, H. (2015), "Dilemma not trilemma: the global financial cycle and monetary policy independence", NBER Working Paper, № 21162, Cambridge, Massachusetts, Oficina Nacional de Investigaciones Económicas.

Hirschman, A. (1961), La estrategia del desarrollo económico, Fondo de Cultura Económica.

Johansen, S. (1988), "Statistical analysis of cointegrating vectors", Journal of Economic Dynamics and Control, vol. 12, № 2-3, Amsterdam, Elsevier.

Kaldor, N. (1978), "The effect of devaluations on trade in manufactures", Further Essays in Applied Economics, Londres, Duckworth.

- (1966), Causes of the Slow Rate of Economic Growth of the United Kingdom. An Inaugural Lecture, Cambridge, Cambridge University Press.

Kaltenbrunner, A. (2010), "International financialization and depreciation: the Brazilian real in the international financial crisis", Competition and Change, vol. 14, № 3-4, Sage.

(2008), "A Post-Keynesian Look at the Exchange Rate Determination in Emerging Markets and its Policy Implications: the Case of Brazil", documento presentado en la $12^{\mathrm{a}}$ Conferencia "Macroeconomic Policies on Shaky Foundations - Whither Mainstream Economics?", Berlín, 31 de octubre-1 de noviembre.

Keynes, J. M. (2003), Teoría general de la ocupación, el interés y el dinero, Ciudad de México, Fondo de Cultura Económica.

(1923), A Tract on Monetary Reform, Londres, Macmillan.

Krugman, P. (1991), "History versus expectations", The Quarterly Journal of Economics, vol. 106, № 2, Oxford, Oxford University Press.

Krugman, P. y L. Taylor (1978), "Contractionary effects of devaluation", Journal of International Economics, vol. 8, No 3, Amsterdam, Elsevier.

Lewis, W. A. (1954), "Economic development with unlimited supplies of labor", The Manchester School, vol. 22, N², Wiley.

Lucas Jr., R. E. (1988), "On the mechanics of economic development", Journal of Monetary Economics, vol. 22, No 1, Amsterdam, Elsevier.

Marconi, N. (2012), "The industrial equilibrium exchange rate in Brazil: an estimation", Revista de Economia Política, vol. 32, № 4, São Paulo.

Myrdal, G. (1957), Economic Theory and Underdeveloped Regions, Londres, Duckworth.

Nassif, A. (2008), "Há evidências de desindustrialização no Brasil?", Revista de Economia Política, vol. 28, № 1, São Paulo.

Nassif, A., C. Feijó y E. Araújo (2015a), "The BRICS's long term economic performance" [en línea] https:// www.boeckler.de/pdf/v_2015_10_24_nassif.pdf.

(2015b), "Structural change and economic development: is Brazil catching up or falling behind?", Cambridge Journal of Economics, vol. 39, № 5, Oxford University Press.

(2011), "The long-term 'optimal' real exchange rate and the currency overvaluation trend in open emerging economies: the case of Brazil”, UNCTAD Discussion Papers, № 206, Ginebra, Conferencia de las Naciones Unidas sobre Comercio y Desarrollo (UNCTAD).

Obstfeld, M. y K. Rogoff (1996), Foundations of International Macroeconomics, Cambridge, Massachusetts, The MIT Press.

Ostry, J. D., A. R. Ghosh y M. Chamon (2012), "Two targets, two instruments: monetary and exchange rate policies in emerging market economies”, Staff Discussion Notes, № 12/01, Washington, D.C., Fondo Monetario Internacional (FMI).

Ostry, J. y otros (2011), "Managing capital inflows: what tools to use?", Staff Discussion Notes, № SDN/11/06, Washington, D.C., Fondo Monetario Internacional (FMI). 
Prasad, E., R. Rajan y A. Subramanian (2006), Foreign Capital and Economic Growth, Washington, D.C., Fondo Monetario Internacional (FMI).

Prebisch, R. (1949), El desarrollo económico de la América Latina y algunos de sus principales problemas (E/CN.12/89), Santiago, Naciones Unidas.

Razin, O. y S. M. Collins (1999), "Real exchange rate misalignments and growth", The Economics of Globalization: Policy Perspectives from Public Economics, A. Razin y E. Sadka (eds.), Cambridge, Cambridge University Press.

Rodrik, D. (2008), "The real exchange rate and economic growth", Brookings Papers on Economic Activity, vol. 39, N², Washington, D.C., The Brookings Institution.

Rogoff, K. (1996), "The purchasing power parity puzzle", Journal of Economic Literature, vol. 34, N², Nashville, Tennessee, American Economic Association.

Romer, P. M. (1986), "Increasing returns and long-run growth", Journal of Political Economy, vol. 94, № 5, Chicago, The University of Chicago Press.

Ros, J. (2014), "Productividad y crecimiento en América Latina: ¿por qué la productividad crece más en unas economías que en otras?”, Desarrollo Económico (LC/MEX/L.1145), Ciudad de México, sede subregional de la CEPAL en México.

Rosenstein-Rodan, P. N. (1943), "Problems of industrialization of Eastern and South-Eastern Europe", Economic Journal, vol. 53.

Sarno, L. y M. P. Taylor (2002), "Purchasing power parity and the real exchange rate", IMF Staff Papers, vol. 49, N 1, Washington, D.C., Fondo Monetario Internacional (FMI).

Simonsen, M. H. y R. P. Cysne (1995), Macroeconomia, São Paulo, Editora Atlas.

Solow, R. M. (1956), "A contribution to the theory of economic growth", Quarterly Journal of Economics, vol. 70, N 1, Cambridge, Massachusetts, The MIT Press.

Subbarao, D. (2014), "Capital account management: toward a new consensus?", What Have We Learned? Macroeconomic Policy after the Crisis, G. Akerlof y otros (eds.), Cambridge, Massachusetts, The MIT Press.

Swan, T. W. (1956), "Economic growth and capital accumulation", Economic Record, vol. 32, N 1, Wiley.

Taylor, A. M. y M. P. Taylor (2004), "The purchasing power parity debate", NBER Working Paper, N 10607, Cambridge, Massachusetts, Oficina Nacional de Investigaciones Económicas.

Verdoorn, P. J. (1949), "Fattori che regolano lo sviluppo della produttivitá del lavoro. L'industria". Publicado también como "Factors that determine the growth of labour productivity", Italian Economic Papers, L. Pasinetti (ed.), vol. II, Oxford, Oxford University Press, 1993.

Williamson, J. (2008), "Exchange rate economics", Documento de Trabajo, Nº 08-3, Washington, D.C., Peterson Institute for International Economics. 


\section{Anexo A1}

\section{Descripción de las variables y las fuentes de la base de datos}

$R E R$ es el indicador del tipo de cambio real efectivo obtenido de la serie 11752, disponible en la base de datos del Banco Central del Brasil [en línea]

https://www3.bcb.gov.br/sgspub/localizarseries/localizarSeries.do?method=prepararTelaLocalizarSeries.

$Y$ es el PIB real per cápita en dólares. Esta variable se estimó a partir de la división de la serie 4385 de PIB mensual en dólares por la serie 21774 de población en el año analizado (estimación del IBGE), ambas disponibles en la base de datos del Banco Central del Brasil (véase dirección de Internet más arriba). El dato de población de 1999 se refiere a la serie 7330.

ToT es el índice de la relación de intercambio de la Fundación Centro de Estudios de Comercio Exterior (FUNCEX), obtenido en IPEADATA, disponible [en línea] http://www.ipeadata.gov.br/.

$C C$ es el saldo en cuenta corriente expresado en relación con el PIB, calculado por la razón de la serie 2731 de saldo mensual en transacciones corrientes por la serie 4385 de PIB mensual, ambas disponibles en la base de datos del Banco Central del Brasil (véase dirección de Internet más arriba).

IDIFER es el diferencial entre la tasa de interés mensual a corto plazo interna (permuta financiera prefijada a 360 días) y la tasa de interés mensual a corto plazo internacional (tasa objetivo de los fondos federales de los Estados Unidos), ambas disponibles [en línea]

https://www.blumberg.com/?utm_source=Microsoft\&utm_medium=cpc\&utm_campaign=BLUM.

$R I$ es el acervo de reservas internacionales, expresado como proporción del $\mathrm{PIB}$, calculado por la razón de la serie 3546 de acervo de reservas internacionales por la serie 4385 del PIB, ambas disponibles en la base de datos del Banco Central del Brasil (véase dirección de Internet más arriba).

$C R$ es el indicador de la prima de riesgo del Brasil representada por el índice de bonos de mercados emergentes (EMBI) relativo al Brasil de JP Morgan, disponible [en línea] www.macrodadosonline.com.br. 